BNL-114550-2017-IR

CBETA/016

June 2017

\title{
TM 4: Beam through the Main Linac Cryomodule
}

\author{
A. Bartnik
}

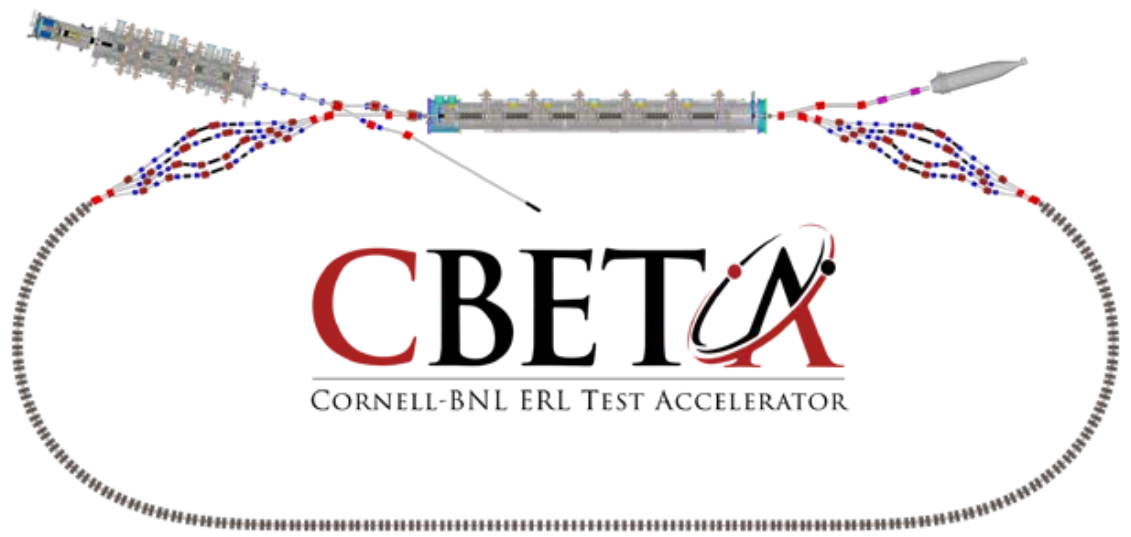

Collider-Accelerator Department, Brookhaven National Laboratory, Upton NY 11973

U.S. Department of Energy

Office of Science, Office of Nuclear Physics

Cornell Laboratory for Accelerator-Based Sciences and Education, Ithaca, NY 14850

Funded by NYSERDA contract 102192

Notice: This document has been authorized by employees of Brookhaven Science Associates, LLC under Contract No. DE-SC0012704 with the U.S. Department of Energy. The United States Government retains a non-exclusive, paid-up, irrevocable, world-wide license to publishor reproduce the published form of this document, or allow others to do so, for United States Government purposes. 


\section{DISCLAIMER}

This report was prepared as an account of work sponsored by an agency of the United States Government. Neither the United States Government nor any agency thereof, nor any of their employees, nor any of their contractors, subcontractors, or their employees, makes any warranty, express or implied, or assumes any legal liability or responsibility for the accuracy, completeness, or any third party's use or the results of such use of any information, apparatus, product, or process disclosed, or represents that its use would not infringe privately owned rights. Reference herein to any specific commercial product, process, or service by trade name, trademark, manufacturer, or otherwise, does not necessarily constitute or imply its endorsement, recommendation, or favoring by the United States Government or any agency thereof or its contractors or subcontractors. The views and opinions of authors expressed herein do not necessarily state or reflect those of the United States Government or any agency thereof. 
CBETA Technical Note 16

\section{$\mathrm{CBET} \mathscr{A}$}

Adam Bartnik for the CBETA Team

June 14, 2017

\section{TM 4: Beam through the Main Linac Cryomodule}

On May 15th 2017, the CBETA project reached the major funding milestone, "Beam through the MLC." For this test, the team had to successfully accelerate the electron beam to 6 $\mathrm{MeV}$ in the Injector Cryomodule (ICM), and then to a final energy of $12 \mathrm{MeV}$ in the Main Linac Cryomodule (MLC). The MLC contains six superconducting accelerating cavities; for this initial test only a single cavity was powered. Details of the experiment are as follows.

After 4:00 pm, we roped off and locked up the CBETA area, as required for a radiation survey of the area at $12 \mathrm{MeV}$. Initial work focused on preparing the RF in MLC cavity 2 (this is the 2 nd closest to the beam stop) for the beam test, and continued until 8:00 pm. In more detail, we turned on the MLC and tuned cavity \#2 in klystron loop at $3 \mathrm{MeV}$ without microphonics compensation. We then slowly raised cavity voltage to a peak of $10 \mathrm{MeV}$ (without electron beam) with compensation on. Importantly, the target setpoint for CBETA operation is only 6 $\mathrm{MeV}$, so the microphonics compensation allowed for a significant improvement beyond that target. Following that, we turned on the ICM, buncher, and gun, and restored the RF and magnet machine settings to their baseline setpoints, set a few days prior. After turning on the laser, no additional machine tuning was required - the electron beam was already through to the beam stop viewscreen. Turning on the MLC to the target $6 \mathrm{MeV}$ energy gain setpoint, we phased the MLC on-crest (Figure 1), ensuring that the full acceleration was delivered to the electron beam. As expected, the total BPM arrival phase change is only 3 degrees, due to the short distance between the RF cavity and BPM. But, we were still able to have more than sufficient BPM resolution to adequately phase the cavity. Now that we had verified that the electron beam was being accelerated to the full $12 \mathrm{MeV}$, we recorded an image of the beam on the beam stop viewscreen (Figure 2).

After that, we removed the viewscreen and increased the current to 1 microamp for a radiation survey of the perimeter of the CBETA area. During the survey, we tested John Dobbins's beam loss monitoring fiber, and recorded the results for later analysis. Radiation levels slightly above ideal were seen within a 6 foot radius of the east entrance, and we will have to remedy this before daytime operation can proceed, with a simple modification to extend the perimeter near the east entrance. At 10:00 pm, we turned off the beam, and surveyed the interior of the area to check for residual radiation from activation of the beam stop area. We saw nothing above a normal background, and therefore no additional precautions were necessary.

Though many tests of the MLC have been performed prior to this, this milestone is both the first test of the MLC with an electron beam, and also the first test of the LLRF system's ability to regulate and stabilize the cavity field, made difficult by the exteremely high $\mathrm{Q}$ of the cavity and the presence of microphonics from the helium vessel. It is also the first time all 
accelerating systems from the elecron source to the Main Linac Cryomodule have been operated together and with beam. Despite these challenges, and the aggressive schedule of the CBETA project, this test has been completed more than 3 months ahead of schedule.

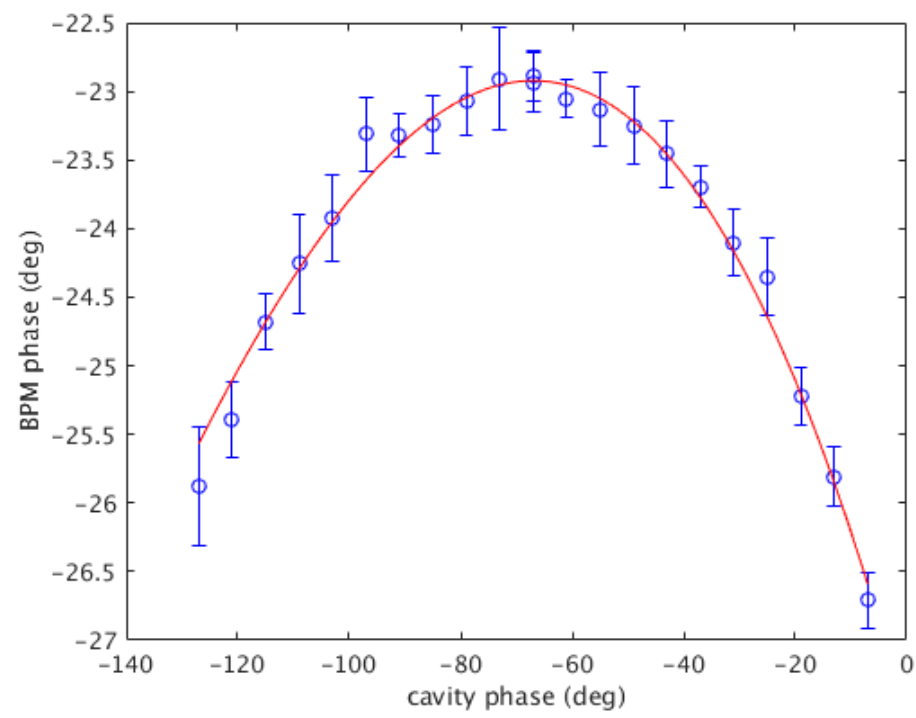

Figure 1: BPM arrival phase as a function of cavity phase. At the peak of the plot, the beam had reached the full $12 \mathrm{MeV}$.

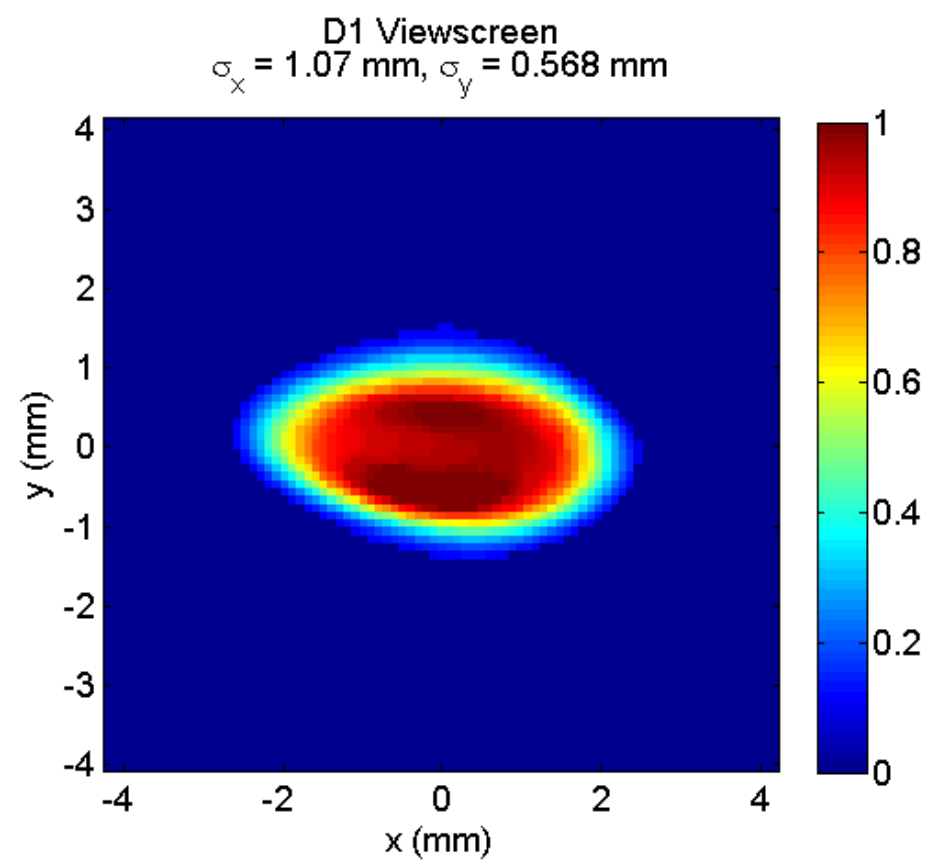

Figure 2: Viewscreen image of the $12 \mathrm{MeV}$ electron beam on the screen right before the beam stop, after the MLC. 